BJHS, 2000, 33, 387-406

\title{
Presidential address: remembrance of science past
}

\author{
LUDMILLA JORDANOVA*
}

\begin{abstract}
Commemoration is a theme to which historians are paying increasing attention, especially to its manifestations in the twentieth century and in relation to war. The formal remembrance of science is an important historical phenomenon, which demands approaches that take account of its distinctive and highly complex relationships with public life. Over the last four hundred years, peer groups and specialized institutions have sought to celebrate selected achievements and to bring those achievements to wider audiences. This address discusses some of the devices and ideas by means of which innovations were turned into cultural items that could be disseminated. Such items included portraits and monuments. As its main examples, the address uses Edward Jenner and vaccination, and the marking of anniversaries.
\end{abstract}

Edward Jenner, the much-fêted discoverer of vaccination, was born on 17 May 1749. In 1807 he received a request from Dr John Reyss, a request of a type that was quite common in scientific and medical circles during the nineteenth century. Reyss, writing from Poland, wanted a portrait of a man he hugely admired as 'the illustrious exterminator of that pestilential disorder, the small-pox'. ${ }^{1}$ In the end he received a bust, as, a few years later, did Jenner's biographer, close friend and fellow medical practitioner, John Baron, who recounted the story in the Life that appeared in a full version in 1838. However, Reyss made a further request, one that makes us smile but demands to be taken seriously. According to Baron, Reyss also asked for 'a small pattern of the cloth that he [Jenner] generally wore, that he and his friends might wear the same garb on the 17th May, the birthday of the DISCOVERER OF VACCINATION'. According to Baron, the bust of himself that Jenner used for gifts, which was by Manning, 'is indeed an extremely faithful and valuable likeness'. ${ }^{2}$

Reyss was searching for ways of commemorating and paying homage to a person who held particular significance for him. He wanted a likeness, and he also wanted to mark an anniversary, a specific day, by behaving in a way that was rich in significance. To wear

\footnotetext{
* School of World Art Studies and Museology, University of East Anglia, Norwich NR4 7TJ, UK. For their encouragement and kindness, I give warm thanks to Janet Browne and Crosbie Smith, exemplary editors. This address was delivered at the BSHS Meeting 'On time: history, science and commemoration' at Liverpool Maritime Museum, September 1999.

$1 \mathrm{~J}$. Baron, The Life of Edward Jenner, 2nd edn., 2 vols., London, 1838, ii, 96. The Life was first published in a single volume in 1827. Other biographical accounts include D. Fiske, Dr. Jenner of Berkeley, London, 1959; R. Fisher, Edward Jenner 1749-1823, London, 1991. See also W. Lefanu, A Bio-Bibliography of Edward Jenner 1749-1823, London, 1951, 2nd edition 1985.

2 Baron, op. cit (1), ii, 96-7; there are several prints of busts of Jenner listed in R. Burgess, Portraits in the Wellcome Institute, London, 1973, 187-9; one of these was used as a frontispiece to Baron's biography. See L. Jordanova, Defining Features: Medical and Scientific Portraits 1660-2000, London, 2000, 118.
} 
clothes modelled upon another person's is to epitomize the saying 'imitation is the sincerest form of flattery', and constitutes a specific form of emulation. Indeed, the theme of emulation is everywhere in scientific and medical writings of the period.

Here is a topic that combines the four principal themes of this BJHS special issue: in the celebration of anniversaries we find time, history, science and commemoration present. Of late we have become accustomed to the hype surrounding anniversaries of key events, the bicentenary of the French Revolution in 1989 being one of the most striking examples by virtue of the epidemic of academic opportunism that it occasioned. In the history of science, we tend to be attentive to anniversaries of birth, death and publication. The British Society for the History of Science newsletter, for example, publishes an annual list of the dates of birth and death of significant individuals. Whatever form the celebration of anniversaries takes, certain core elements are present, which are especially prominent when individuals are involved. There is a reference to an exact moment in the past of special symbolic significance, which becomes the occasion for some act of paying tribute. That is, anniversaries involve recognition, celebration and commemoration. As a result, they mark the passing of time in a quite precise manner, through which we are drawn not only to remember but also to measure our exact distance from an event.

But why, we ought to be asking, is remembrance important at all, and why should it take the form of marking anniversaries ? ${ }^{3}$ We might also probe the appeal of birthdays in particular since they are, in a number of respects, arbitrary and accidental markers. There has been such a surge of interest among historians in the theme of commemoration in recent years that it is all too easy to take for granted some deep-seated need for expressions of collective memory. ${ }^{4}$ Yet I do not think that we should see this phenomenon as a given or as a psychological constant. Forms of remembrance are historically specific and very often locally forged. By 'local' I do not mean parochial or limited but responsive to particular circumstances, such as time, place or occupation. A field such as medicine, for example, may at a given moment cultivate characteristic ways of celebrating its past, and at the level of detail these ways are likely to be peculiar to it and not shared by, say, contemporary lawyers or churchmen. Furthermore, the cult of Hippocrates, which was a widespread phenomenon, has taken many forms. ${ }^{5}$ At some periods it was much more intense, immediate and alive than at others. In other words, what is remembered is always actively shaped by those who remember, by the imperatives they experience most vividly. These processes generally involve a fair amount of repetition: repeated motifs affirm a sense of continuity, yet each time they are used subtle changes are introduced to suit their moment of reuse.

3 J. Fentress and C. Wickham, Social Memory, Oxford, 1992 is full of insights; see also R. Quinault, 'The cult of the centenary, c. 1784-1914', Historical Research (1998), 71, 304-24.

4 Examples of recent work on commemoration are J. Gillis (ed.), Commemoration: The Politics of National Identity, Princeton, 1993; J. Winter, Sites of Memory, Sites of Mourning: The Great War in European Cultural History, Cambridge, 1995.

5 An example would be the preoccupation with a limited number of ancients at any given time. I have tried to explore this in The Sense of a Past in Eighteenth-Century Medicine, Reading, 1999. On Hippocrates, see A. Heidel, Hippocratic Medicine: Its Spirit and Method, New York, 1941; R. J. Bulger (ed.), Hippocrates Revisited: A Search for Meaning [New York, 1973]; W. D. Smith, The Hippocratic Tradition, Ithaca, NY, 1979. 
Two aspects of much recent work on commemoration are striking to me. First, it pays greatest attention to the twentieth century, in other words to responses to events still within living memory, and which have been and still are being explored in many cultural forms, such as poetry, film, novels and so on. I think this emphasis has been unfortunate because it reinforces a particular kind of modernism, one that, to take its most obvious aspects, sees the First World War as a special turning point and assumes the fresh significance of memory for a psychoanalytic age. ${ }^{6}$ One result is a neglect of a longer view, and possibly also of historiographical styles capable of drawing together the ideas of those working on different periods; it is as if the world of relics and the world of shell shock demand totally different conceptual frameworks. Yet the very notion of a relic and its accompanying mindset, which place a kind of magic in a restricted number of objects, is clearly central for recent science and its public faces. However historically specific forms of remembrance are, there is much to be gained by more openness to insights and approaches from diverse periods. Second, recent work on commemoration is, I think, implicitly struggling with ways of understanding public, mass cultures. 'Public' is a notoriously difficult term regardless of the discipline in which it is used, and some kinds of commemoration appear to give access to it in a rather straightforward way. The concern with memorials connected with the two world wars is an excellent example, but it is not necessarily sound to think about all kinds of public commemoration in the same way. What might we mean by 'public' in this context? Out in the open, widely accessible, addressing large, even implicitly universal audiences, expressing shared values, drawing upon a recognized collectivity of some sort would all seem to be important elements. ${ }^{7}$ It goes without saying that the tangible forms of remembrance are extraordinarily diverse. They range from the large and conspicuous, Lutyens's Cenotaph unveiled in London in 1920, for example, through highly conventionalized forms, such as busts and statues, to the mundane, such as street names. ${ }^{8}$ The mundane would also include Bath Oliver biscuits, named after the eighteenth-century Bath physician, an example that certainly challenges concepts of 'public'. ${ }^{9}$ Also in this category are banknotes, ${ }^{10}$ and promotional items such as Sainsbury's 'Makers of the Millennium', a series of 'medals' that included figures such

6 History Workshop Journal has been particularly responsive to the possibilities psychoanalysis offers to the discipline of history, for example, K. Figlio, 'Oral history and the unconscious', History Workshop Journal (1988), No. 26, 120-32; K. Figlio, 'Historical imagination/psychoanalytical imagination', History Workshop Journal (1998), No. 45, 199-221 - both part of special issues on psychoanalysis and history. See also A. Scott, Real Events Revisited: Fantasy, Memory and Psychoanalysis, London, 1996.

7 'Public' is also about government and the institutions of the state. My concern here, however, is with widely accessible forms of cultural display, a related but separable issue. Readers should note that I am not assuming the existence of a separate 'public sphere'; see note 11 below.

8 Sir Edwin Lutyens (1869-1944), London, 1981, 148-55, 149; on busts, see D. McKitterick (ed.), The Making of the Wren Library, Trinity College, Cambridge, Cambridge, 1995, Chapter 4.

9 Jordanova, op. cit. (2), 74.

10 Michael Faraday was on the $£ 20$ note; M. Pointon, 'Money and nationalism', in Imagining Nations (ed. G. Cubitt), Manchester, 1998, 229-54. 
as James Watt. In order to explore what, if anything, is distinctive about the remembrance of science, I want to probe a little further some aspects of the notion of 'public'. ${ }^{11}$

Most of us have grown up with war memorials as unremarked parts of the ordinary environment. ${ }^{12}$ At the same time we have been surrounded by family memories, films, stories, books, poetry and so on about the two world wars which provide some sense of context, however invented, and which can be drawn upon as and when required. I could put the same point a bit differently by noting that these wars involved, in one form or another, virtually everybody. It is possible to visit many of the key sites (battlefields and war cemetaries), and related issues (guilt and reparation) constantly arise in the media. Opinions on these wars differ dramatically, but there are nonetheless received ways of remembering them that few openly dissent from and many are drawn into through accumulated emotional tugs. The ubiquitous use of the poppy to evoke the First World War and the obligation felt by most Britons to buy one every November make the point. Thus by many means 'history', 'commemoration' and 'time', if I can use these concepts as shorthand, seep into public culture. ${ }^{13}$ To illustrate these themes I have used phenomena, the two world wars, the reach of which was both wide and deep. My concern here, however, is specifically with the remembrance of science, which could not be more different. These differences emerge more clearly in comparisons with other forms of remembrance.

The production of scientific knowledge is not accomplished through mass participation. The practice of science, medicine and technology has, for at least two hundred years, involved specialized training, equipment, infrastructure and settings. Such activities are, necessarily, infused with the social relations and value systems of their parent society, but they remain in significant ways set apart from ordinary existence. I am not assuming any rigid distinction between the production and deployment of knowledge in pointing out that some forms of remembrance depend on the lived experience of significant swathes of the population, while others relate to activities that are considerably more esoteric. Whatever their ultimate effect on social life, scientific domains are not integrated into most people's experience, awareness of them is not transmitted in quotidian intimate relationships, they are evident in a rather restricted proportion of cultural products and there is little public access to the places where they are practised. Science is commemorated in a sporadic

11 It is now customary to refer to Habermas whenever the notion of 'public' comes up. C. Calhoun (ed.), Habermas and the Public Sphere, Cambridge, MA and London, 1992 is useful; cf. T. Broman, 'The Habermasian public sphere', History of Science (1998), 36, 123-49. Historians of science have become increasingly concerned with notions of the public, especially in the eighteenth century: L. Stewart, The Rise of Public Science: Rhetoric, Technology, and Natural Philosophy in Newtonian Britain, 1660-1750, Cambridge, 1992; J. Golinksi, Science as Public Culture: Chemistry and Enlightenment in Britain, 1760-1820, Cambridge, 1992; A. Morton and J. Wess, Public and Private Science: The King George III Collection, Oxford, 1993; C. Withers, 'Towards a history of geography in the public sphere', History of Science (1999), 37, 45-78.

12 A. Borg, War Memorials: From Antiquity to the Present, London, 1991; A. King, Memorials of the Great War in Britain: The Symbolism and Politics of Remembrance, Oxford, 1988; J. Young, The Texture of Memory: Holocaust Memorials and Meaning, New Haven, 1993; J. Young (ed.), The Art of Memory: Holocaust Memorials in History, Munich, 1994.

13 B. Taithe, 'Monuments aux morts? Reading Nora's Realms of Memory and Samuel's Theatres of Memory', History of the Human Sciences (1999), 12, 123-39. 
fashion, almost totally out of context; what results is the 'remembrance' of an activity which is, increasingly, almost totally mysterious to the general public. Is it not a little ironic to publicly celebrate something that certainly impacts upon the masses but from which in a number of significant ways they are estranged? Thus the knowingly naive questions I posed above really do need to be asked here: why remember, and why anniversaries?

These issues have never been more pertinent than they are now when the British scientific and medical establishments are promoting the 'public understanding' of their field. The resources being poured into such activities are very considerable, but they do not involve informing the public about the processes whereby knowledge is produced. Rather, they promote key ideas, achievements, techniques and innovations as worthy of, among other things, celebration. This is partly accomplished by glamourizing them, by creating cultural items that are easily disseminated in order to induce in those not involved in the production of such knowledge a sense of gratitude and admiration, perhaps even of awe. As I shall suggest, the remembrance of science involves precisely such maneouvres.

I discuss these questions using selected examples, principally Edward Jenner (1749-1823). The jolly, unpretentious country surgeon, whose 'great discovery' was vaccination, is a particularly interesting case study in scientific and medical heroism and its commemoration. ${ }^{14}$ Given his extraordinary prestige in his own time and his unique historical position as the 'discoverer' or 'inventor' of a technique that eventually (in 1979 or 1980 according to which authority is cited), did eradicate the terrible disease of smallpox, surprisingly little of a scholarly nature has been written about Jenner. Yet from 1796, when he performed his first experiment on vaccination, he was repeatedly celebrated and commemorated in objects, exhibitions, meetings, texts and so on. Remembering Jenner involved giving historical accounts, activating a sense of his achievement by tangible means, marking key dates such as his birth and death, and keeping his relevance alive. It is perfectly clear that remembering also involves acknowledging how much worse things were before, so that progress can be repeatedly affirmed - in effect this is a claim about the lessons of history. ${ }^{15}$ Such remembrance involved, in other words, time, history and commemoration. And, although a surgeon, Jenner was of broad significance for 'science', since he was understood as an observer and experimenter. ${ }^{16}$

14 The phrase 'great discovery' is Derrick Baxby's: Jenner's Smallpox Vaccine: The Riddle of Vaccinia Virus and its Origin, London, 1981, p. vi.

15 A recent example is H. Bazin, The Eradiction of Smallpox: Edward Jenner and the First and Only Eradication of a Human Infectious Disease, London and San Diego, 2000, especially Section 1, entitled 'For those who have forgotten or never knew what smallpox was like'.

16 Publications on Jenner are numerous, for example: 'Commemorating the conqueror of small-pox: the centenary of Jenner, discoverer of vaccination', Illustrated London News, 27 January 1923, 122-4; Académie de Médecine, Centième Anniversaire de la mort de Jenner, Paris, 1923; P. Razzell, Edward Jenner's Cowpox Vaccine: The History of a Medical Myth, 2nd edn., Firle, Sussex, 1980; D. Baxby, 'An unusual portrait of Edward Jenner and a possible link with Napoleon', Medical History (1978), 22, 335-9; S. Jonas, Cent Portraits de médecins illustres, Paris, 1960, 119-21; E. Underwood and A. Campbell, Edward Jenner: The Man and his Work, Bristol, 1967; J. Empson, 'Edward Jenner, slayer of the "speckled monster"', World Health Forum (1996), 17, 351-3; J. Empson, 'Little honoured in his own country: statues in recognition of Edward Jenner MD FRS', Journal of the Royal Society of Medicine (1996), 89, 514-18; The Chantry: Dr Edward Jenner's Home 1785-1823, [1986], (publication of the Jenner Museum, Berkeley, Gloucestershire). 
At this juncture I want to make clear how I am using the term 'science'. The British Society for the History of Science is conceived as a broad church, thus in this context 'science' may be taken to include natural history, the biological and physical sciences, mathematics, applied sciences, such as engineering, and medicine. However, all these fields have to be used and defined by scholars according to context. We try to understand actors' categories and this involves being attentive both to the ways in which broad terms, such as 'science', have been invoked, and to the changing and varied terminology used of more delimited domains. Jenner, for example, was a medical practitioner with strong interests in natural history. Although he was a surgeon, he was also claimed by physicians. His innovation was taken to be broadly scientific in that it consisted of a method that had been tested experimentally and thereby refined. Indeed it was perceived as an exceptional intellectual advance. We are attentive to historical changes in the names of domains of natural knowledge precisely because these are laden with assumptions about how the world should be divided up and the manner in which it should be approached. Terminology changes according to context: there have been times when the lineage of a specific discipline has been affirmed - Boyle as the father of chemistry, for example - and others when the general value of an innovation is paramount. In the latter cases, more generic claims about intellectual, scientific or medical value are appropriate.

It is important to be explicit about the fact that I am thinking of a particular period in talking about the remembrance of science past. I have in mind the era from the late seventeenth century to the present day. ${ }^{17}$ With respect to this theme it forms a natural period, which is to say that continuous traditions of recognition and commemoration were established over that time for a wide range of scientific, technological and medical activities. Since the word scientist was coined in the 1830s, for much of this period there was no single word for the range of people actually commemorated. Varied descriptions of occupation and achievement were used, and the rather unspecific 'man of science' was a fairly common term. In terms of public recognition, those accorded most were associated with particular innovations, ideas or discoveries, and I would suggest that, by that token, they were celebrated for an intellectual leap. If such a leap was not readily apparent in the work of someone whom it was otherwise important to commemorate, then it or something very like it had to be fashioned. Such leaps became useful cultural currency that enabled specialized communities to celebrate their own and bring their achievements to larger audiences. These devices were important because, as I have already pointed out, the actual production of scientific and medical knowledge is somewhat distanced from the majority of the population, who may be dramatically affected by it but have virtually no involvement in it. I would further argue that this is not a new phenomenon, despite the fact that the processes by which such knowledge is produced have indeed changed markedly since the late seventeenth century. Because of this distance, public recognition of scientific

17 In Defining Features (Jordanova op. cit. (2)), I take the years 1660-2000 as forming a natural period, since the foundation of the Royal Society marked a highly significant turning point not just in terms of a nascent sense of collective intellectual activity, but more significantly in the collection of items, such as portraits, that served to remind people of past and current achievements. In this context, I would argue, the precise field of study any given individual was involved in was less important than other factors, such as making an intellectual leap, hence it seems reasonable to use the term 'science' to register this broad interest. 
and medical achievement can only take place if bridges are built. These take the form of tags, flexible cultural units if you like, that can easily be assimilated and disseminated in a variety of forms. These units have to have a human dimension, hence the interest in representations of the people who actually do the achieving, and perhaps also in aspects of them, such as birthdays, which they share with all other human beings and by that token invite identification.

In Jenner's case, all this came ready-made, as it were, and it consisted of four interrelated elements: the cow, a single terrible disease, the idea of efficacy and humanitarianism. The existence and effective employment of such tags perhaps accounts, at least in part, for the rapid and phenomenal rise in Jenner's reputation, and for the speedy dissemination of vaccination. They also played a part in the bitter conflicts it aroused. The discovery of something that can be treated as a unitary phenomenon and associated with an individual person is an effective bridge between a specialized endeavour and wider publics. Note that I have not made much of Jenner's personal characteristics. Although there were traits and forms of behaviour that would generally have been regarded as unacceptable by fellow practitioners, by and large anyone could be turned into a scientific or medical hero if necessary. It would be mistaken to think that there was a rigid set of criteria already in existence. Rather, aspects of an individual were selected and molded - we might say that this was the original form of spin-doctoring, which is particularly evident in biographical accounts.

The celebration of technological achievement, at any rate in some of its forms, would seem to work slightly differently in that there is more often a physical object to do some of this cultural work. For example, we could cite in accounts of James Watt the constant interplay between him and his engine as objects inspiring awe and identification. ${ }^{18}$ Joseph Wright of Derby's magnificent 1789-90 portrait of Sir Richard Arkwright, with its precise depiction of a set of cotton-spinning rollers, is another case in point. ${ }^{19}$ In the case of Jenner, objects could be found to do such jobs, but they tended to be rather special kinds of object, mostly non-scientific ones.

So if science was not a mass phenomenon, who did the remembering? Institutions played a major role here: their collections of portraits, books, instruments and specimens acted as memory-prompts, so did many of their publications, collective activities, buildings and named lectures. ${ }^{20}$ But often it was through personal networks that effective forms of commemoration were forged. There is ample evidence of the involvement of coteries working to ensure that their particular hero, for want of a better term, received adequate recognition, and in so doing they generally claimed to be speaking on behalf of larger

18 On Watt, see C. MacLeod, 'James Watt, heroic invention and the idea of the industrial revolution', in Technological Revolutions in Europe: Historical Perspectives (ed. M. Berg and K. Bruland), Cheltenham, 1998, 96-116.

19 J. Egerton, Wright of Derby, London, 1990, 197-8 and 256-7 for the print engraved by John Raphael Smith.

20 Longer-established organizations, such as the Royal Society of London and the Colleges of Physicians and of Surgeons, for example in London and Edinburgh, are particularly compelling instances: N. Robinson, The Royal Society Catalogue of Portraits, London, 1980; V. Negus, Artistic Possessions at the Royal College of Surgeons of England, Edinburgh and London, 1967; A. Masson, Portraits, Paintings and Busts in the Royal College of Surgeons of Edinburgh, Edinburgh, 1995. 


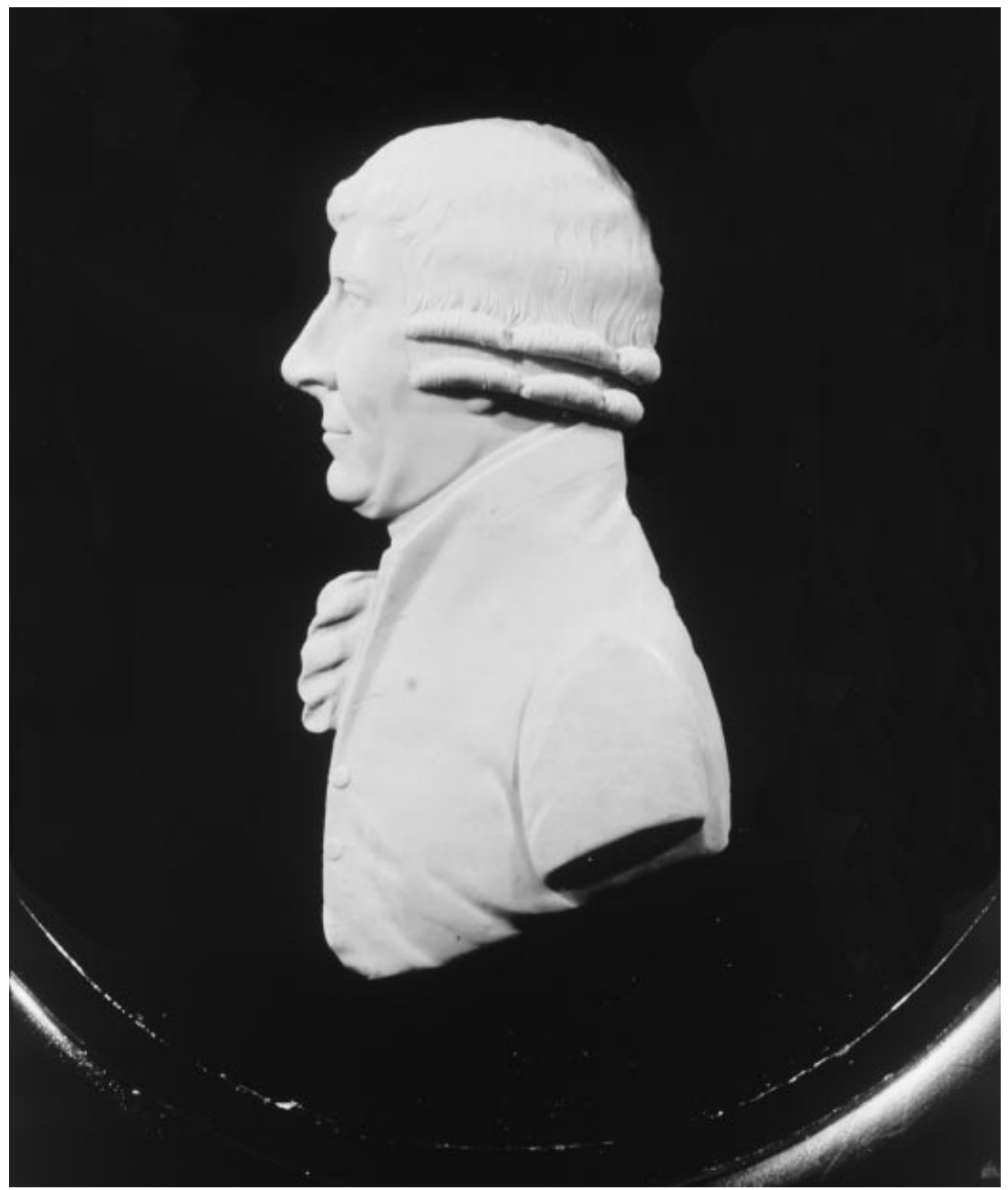

Figure 1. T. R. Poole, John Coakley Lettsom, 1809, pink wax medallion on an oval wooden mount, w. $18 \mathrm{~cm}$. Royal College of Physicians, London.

constituencies. Examples that spring to mind include Isaac Newton, John Hunter, Edward Jenner and Charles Darwin. ${ }^{21}$ In the process such coteries defined their own identities, which were 'backward-looking' and 'forward-looking' simultaneously.

Remembrance takes many forms, and especially within defined groups, its expression is, ideally, apt for that particular community's concerns. So when John Coakley Lettsom (Figure 1) - one of Jenner's bulldogs - presented his ideas on the history of medicine to the

21 M. Jacob, The Newtonians and the English Revolution 1689-1720, Ithaca, NY, 1976; R. S. Westfall, Never at Rest: A Biography of Isaac Newton, Cambridge, 1980; L. S. Jacyna, 'Images of John Hunter in the nineteenth century', History of Science (1983), 11, 85-108; J. Moore, 'Charles Darwin lies in Westminster Abbey', in Charles Darwin: A Commemoration 1882-1982 (ed. R. Berry), London, 1982, 97-113. 
Medical Society of London, a body he helped to found, the match between his agenda and theirs was quite snug. ${ }^{22} \mathrm{He}$ could assume a certain acquaintance with classical sources, with accounts of travels and with what we would call modern history among his fellow medical practitioners. Lettsom owned a library of some six thousand volumes, and he adorned it with the busts of relevant worthies, so that his reading and his remembrance of the past went hand in hand. For Lettsom, as for so many of his contemporaries who were medical practitioners, the past was very much alive. ${ }^{23}$ But there is a complexity lurking here. The groups of practitioners in, say, the eighteenth century, who were remembering the past in order to think about the present and the future of their own fields, inhabited a somewhat different memory world to ours. The relationships between the practice of science and the writing of its histories have undergone significant shifts as the latter became a separate, highly specialized activity in its own right. Although some historians of science and medicine have received training in those areas, if they earn a living from doing history they probably no longer think of themselves as scientists or doctors but as historians - the patterns of identification have changed. As I have suggested elsewhere, we can think of this in terms of dead pasts and various kinds of living pasts - for most practitioners of science, medicine and technology in the twenty-first century, the past is either dead or moribund, for their equivalents in the eighteenth century it was alive and kicking. ${ }^{24}$ Again, there are many distinct ways in which the past can be alive for its practitioners, which vary from time to time, from field to field.

The themes I have been sketching out so far can be seen in three broad forms of remembrance: the writing of histories, portraiture practices and public monuments. Practitioners paid a great deal of attention during the eighteenth century to the generation of historical accounts of their chosen fields. We are now familiar with the complex politics behind John Freind's History of Physic (1725-6) thanks to Julian Martin's splendid article, which examines this Tory, Jacobite Newtonian's account of the medical past. Recounting the history of medicine was for Freind, as for so many others, a form of selective memory, where the past was deployed for totally contemporary purposes. Although a Jacobite and a Tory, Freind was close to fellow Newtonian Richard Mead, a dissenting liberal Whig, for whom the writing of history was also a highly charged activity. When Mead wrote about Roman coins he was exploring the status of Roman medical practitioners, and thinking about the antecedents of his own profession. When he wrote about diseases in the Bible he was thinking about contemporary debates concerning miracles, the regularity of natural laws and the precise conditions under which God was prepared to suspend them

22 J. C. Lettsom, History of the Origin of Medicine, London, 1778. A prize in his name, worth $£ 5000$ in 2000 , is offered by the Medical Society of London for an essay on a specified topic that reflects his interests. Named prizes are a particularly interesting form of remembrance.

23 J. Abraham, Lettsom: His Life, Times, Friends and Descendents, London, 1933; Jordanova, op. cit. (5), $8-13$.

24 Jordanova, op. cit. (5). 
- all hot topics for natural philosophers, especially Newtonians, and also for theologians. ${ }^{25}$ He was also thinking about the treatment of hysteria. When Mead gave a bust of William Harvey to the College of Physicians he was also being a historian, of his own calling and of the institution in question. The bust is now prominently displayed in the entrance hall of Denys Lasdun's splendid building of 1959 on Regent's Park, London, which allows these historical resonances full expression. Even if we restrict ourselves to medicine, it is striking how the conspicuous display of historical knowledge used a highly selective form of memory, as well as the measurement and naming of epochs, to do contemporary business. ${ }^{26}$ The many histories of smallpox and of inoculation techniques were also doing just this. ${ }^{27}$

Histories were not the only form of publication that served a commemorative function for men of science and medical practitioners. The growing interest in biography is a notable feature of the eighteenth century; it is evident in the magazines that published short biographical notices, often accompanied by a portrait, as well as in the compilations of lives that started to appear by the end of the century. Portraits, even more than biographies, provided an immediate sense of what a given practitioner was like. The term 'portraits' embraces a great deal not just in terms of size and medium but in terms of the purposes and the circumstances of their making. ${ }^{28}$ Those associated with scientific and medical institutions are especially relevant to my concerns here. The exceptional significance of Joshua Reynolds's portrait of John Hunter for the Royal College of Surgeons in London is an excellent example. A highly inventive portrait, it is a visual reminder of Hunter as a comparative anatomist, as a distinguished point of origin of a field and as a collector whose possessions sit at the centre of the building where the picture hangs, a building filled with items reminiscent of him. The associations, the symbols, happen to be particularly obvious in this case, but the phenomenon is widespread. There are two main reasons for the centrality of institutions in medical and scientific portraiture. Where buildings exist, which is in most cases, there are opportunities for display, and the point about display is not that it involves showing off but that the portraits on display become a feature of the daily life of those who work in or visit the institution. As a result of repeated viewing, images and their associations are internalized. Whereas anyone can see a public war memorial, few members of the general public enter specialized scientific and medical institutions, so the

25 J. Martin, 'Explaining John Freind's History of Physick', Studies in History and Philosophy of Science (1988), 19, 399-418; Richard Mead gave the Harveian oration on coins in 1723. It was published the following year; his Medica Sacra, London, 1749 (Latin) and 1755 (English) discussed diseases in the Bible. L. Jordanova, 'Richard Mead's communities of belief' in Christianity and Community in the West: Essays for John Bossy (ed. S. Ditchfield), Aldershot, 2001

26 Other examples of histories of medicine from the same period include William Black, An Historical Sketch of Medicine and Surgery, from their Origin to the Present Time, and of the Principal Authors, Discoveries, Improvements, Imperfections and Errors, London, 1781; David Ramsay, A Review of the Improvements, Progress and State of Medicine in the XVIIIth Century. Read on the First Day of the XIXth, Charleston, SC, 1801. Ramsay, a historian of the American republic as well as a medical practitioner, combined celebration of the past with a strong vision of future progress.

27 For example, W. Black, Observations Medical and Political on the Small-Pox and Inoculation; and on the Decrease of Mankind at Every Age, London, 1781; T. Bordeu, 'Recherches sur l'histoire de la médecine' in idem, Oeuvres complètes, 2 vols., Paris, 1818, ii, 548-734.

28 Jordanova, op. cit. (2) sets out some of the basic issues. 
audiences for their portraits are quite select. Yet they are also diverse - often the service and support staff show a special interest in such items. Images of illustrious forebears and contemporaries readily become incorporated into the visual repertoires of peer groups.

The other reason for the significance of portraits in institutions is that the latter are in the business of more or less knowingly generating and cultivating corporate identities. They do so partly through their portraits, which form series and lineages, the professional equivalents of family trees, where the depiction of any given individual can be 'read' in relation to others. Such readings do indeed require specialized, insider knowledge. The whole purpose of portraits is to fix what is taken to be a likeness for contemporary reverence, for posterity and for those who are geographically distant from the sitter, as was the case of Jenner's admirer John Reyss. Once a template exists, many different versions can be generated, such as prints, wax medallions, busts, medals, statues, frontispieces and so on. We should remind ourselves once again how different the uses of these various forms are, from intimate recollection to conspicuous displays of individual or collective achievement. These diverse uses also suggest varied audiences. It should be noted that the uses of portraiture are inseparable from practices of collecting, broadly defined to include business ventures aimed at collectors and institutions collecting on behalf of a nation. We can note the commercial production of series of scientific and medical worthies expressly designed to be put together and of single prints that could be used in a variety of ways, the existence of individual collectors with special interests and the operation of organizations such as the portrait galleries in London and Edinburgh. Expressly designed to honour national achievement, these galleries include many scientific, technological and medical figures, but they do so in a context that is totally different from, say, the Royal Society.

Before turning to the third form of remembrance, I would like to consider briefly the ways in which time is registered in portraits. As historians we are familiar with the ways in which it comes up in the practice of history, with the construction of chronologies, with causal explanation, with reconstructing processes, with the varied paces of different types of change and so on. But portraits, items of visual culture, work with time in their own ways. As works of art, portraits register 'time' in every aspect of their production from 'style' to the type of paint used. That is, their moment of production is made manifest visually. But, in addition, they work with time as an idea, and they do so in three ways. Three examples suggest different ways in which this occurs. First, some portraits evoke earlier epochs as a guiding presence, by archaic clothing and objects, or the presence of classical busts and motifs. Second, it is possible either to omit accoutrements altogether or to deploy visual devices that have become conventionalized and so efface historical specificity - drapery, or 'generalized' tables and chairs, for example. Third, the inclusion of completely contemporary accoutrements suggest a quite specific time. These are three different models of portraiture: associating the sitter with a past, taking them out of precise time and placing them inside a particular moment. ${ }^{29}$ Although we can never be sure how

29 Examples of these types may be found in Jordanova, op. cit. (2), 17 (Cullen with a classical bust); 78, 149 and 151 (Havelock Ellis, Henry de la Beche and Clive Riviere out of time); 126, 137 and 143 (Marie Curie, Olga Kennard and Ada Lovelace in specific times). The third type is perhaps the least common, presumably because the terms of portraiture as a genre include generalizing and elevating sitters, which are more easily accomplished if they are not tied to a particular historical moment by accoutrements, settings, hair or clothing. 
portraits were read in the past, it is worth pointing out that they involve far more than a likeness. In fact they work in a subtle manner to elicit viewers' ideas about commemoration, time and the nature of scientific achievement.

The term 'public monuments', my third form of remembrance, needs to be interpreted rather liberally. We certainly should be thinking about the conventional forms of public commemoration to which historians have been so attentive in recent years: public statues, tombs and memorials, for example. We might also want to think, particularly in relation to cities such as Paris and London, of street names and blue plaques respectively. ${ }^{30}$ In this category I want to include museums, which, together with their retail activities, have become the most prominent public monuments to science that we have. They certainly commemorate and celebrate, they attract large numbers of visitors and enjoy considerable prestige, they attract sponsorship from huge companies, many of them multinationals, and convey the values of the science and industry establishments to people, many of them children, who have little relevant knowledge. In other words, these 'cathedrals of science' are now powerful institutions that mediate between specialists and the general public. Their scope and ambition are indeed monumental - their design suggests as much - and in their intricate blend of past, present and future they prompt, with considerable authority, remembrance of science past. ${ }^{31}$

At this point I want to return to my case study of Edward Jenner with these ideas in mind. More particularly, I want to come back to John Reyss's request. His original letter had been written in Latin, and a translation was read aloud on the occasion of a special gathering of the Jennerian Institution in London. This organization had a troubled history and ceased to exist not long after that particular meeting. It had been formed early in 1803 and received considerable royal and aristocratic support. Its anniversary was celebrated on 17 May, Jenner's birthday. Jenner's age was clearly not the issue, rather it was a specific form of homage to have the anniversary meeting on his birthday. Furthermore, reading Reyss's letter aloud created, or perhaps I should say reinforced and affirmed, the merit of a community that existed because of the work of one man. This suggests that commemoration was an important part of scientific and medical cultures as these were actually being formed. The point is all the more important since both the practice of vaccination and this society in particular were riven with conflict; the intention may have been to use Jenner as a unifying figure, but it did not always work. Commemoration was frequently important because it occurred in the face of countervailing forces, which had to be marginalized, denied or crushed.

There is more to the story. In Baron's words, '[Reyss] complimented Jenner highly on his discovery; [and] sent him a richly embossed silver cup, which had belonged to a person of the name of JENNER'. Baron then records Jenner's speech of thanks, which included the following:

30 N. Rennison, The London Blue Plaque Guide, Stroud, Gloucestershire, 1999, see 213-18 for people listed by profession.

31 S. Sheets-Pyenson, 'Cathedrals of science: the development of colonial natural history museums during the late nineteenth century', History of Science (1987), 25, 279-300; S. Sheets-Pyenson, Cathedrals of Science: The Development of Colonial Natural History Museums during the Late Nineteenth Century, Kingston, Ontario, 1988. 
My native country has complimented me with some very elegant plate; but there is not a piece among it I set so high a value upon as the curious antique cup you have presented to me, and which has probably graced the table of those who sprang from the same stock as myself. ${ }^{32}$

These comments are revealing. Although Jenner's followers stressed his becoming modesty, these words suggest someone acutely aware of their public image. The hint, made much more explicit elsewhere, that his native country had not been sufficiently generous, is striking. The two parliamentary grants Jenner received were frequently cited, but equally his supporters were anxious for more public recognition and accordingly they were fond of reciting a roll-call of international honours. Indeed it is true that subscriptions for two of the statues, one in Gloucester Cathedral and the other originally in Trafalgar Square, were much slower than expected, and in the latter case most of the money came from abroad. Although erected in Trafalgar Square, it was soon moved to the less conspicuous and prestigious location of Kensington Gardens, and Trafalgar Square was dominated by political and military figures. ${ }^{33}$ Jenner's speech of thanks further made it clear that he valued such marks of esteem, and that he felt the pride of lineage associated with his name.

The story involving John Reyss hinged on the capacity of objects to carry the specialness of an individual. It should come as no surprise that there were several public exhibitions of Jenneriana towards the end of the nineteenth century and in the early twentieth century. Indeed sometimes these items were referred to as relics. It was a diverse collection, eventually purchased by Sir Henry Wellcome, including manuscripts, books, portraits, objects, such as medical instruments, and memorabilia. ${ }^{34}$ How do these items work? Provenance is absolutely vital for establishing their significance since visual inspection alone would not suffice. Jenner's snuffbox or spectacles, for example, look no different to those of his contemporaries. When visiting an exhibition we have no choice but to take on trust that these are the very ones he owned and used. And the more objects with an impeccable pedigree can be displayed together, the greater is the sense of historical authenticity that can be experienced. Items such as letters, wills and other documents function rather differently in that visitors can discern some kind of direct meaning from the words, although their status as the genuine article rather than forgeries or copies also has to be taken on trust. But a further leap has to be made: seeing the objects themselves as holding something of their owner or creator within them. The way portraits function is analogous in that we have to concede the (physical) likeness is eloquent about the (character of the) person depicted in order for the picture to be of special value. We have already seen this at work in Jenner's case - Reyss wanted the cloth because it could hold, express or represent Jenner's specialness.

Portraits of Edward Jenner have been widely disseminated, and they continue to be, not

32 Baron, op. cit. (1), ii, 96.

33 Empson, op. cit. (15); Dr G. Prescott Nuding, Royal Institution, London, is currently working on the London statue of Jenner. For a different approach to Jenner's legacy, see C. Lawrence, 'Edward Jenner's jockey books and the great tradition in English medicine', in Regenerating England: Science, Medicine and Culture in Inter-war Britain (ed. C. Lawrence and A.-K. Mayer), Amsterdam, forthcoming.

34 Catalogue of an Exhibition of Books, Manuscripts and Relics Commemorating the Bicentenary of Edward Jenner, 17 May 1749-26 Jan. 1823, London and New York, 1949; exhibitions had also been held in the 1890s: A Catalogue of the Collections of Relics of Dr Edward Jenner, Cardiff, 1896. Jordanova, op. cit. (2), 123, shows Henry Wellcome's display. 


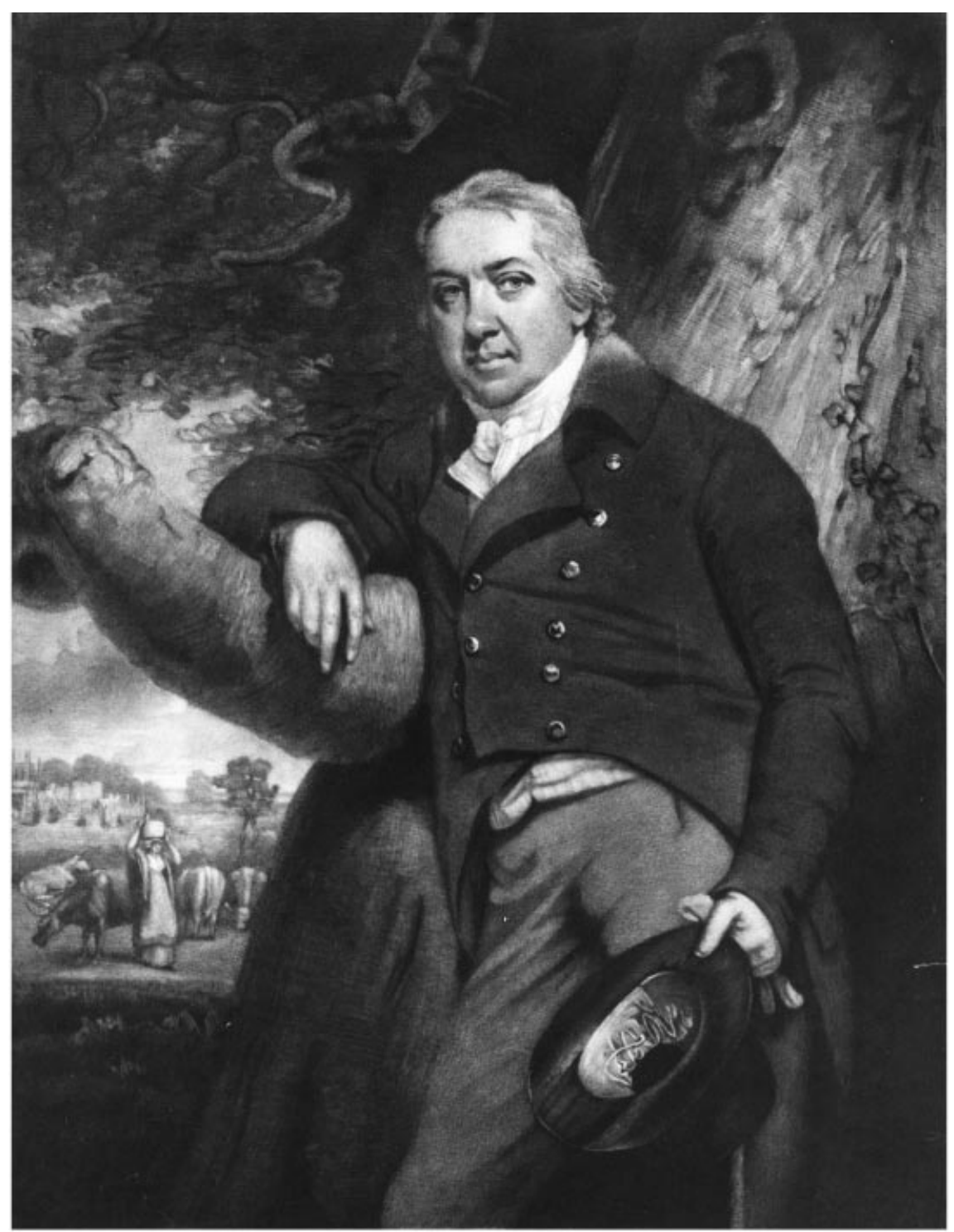

Figure 2. John Raphael Smith, Edward Jenner, 1800, mezzotint, $45.2 \times 35 \mathrm{~cm}$. This print is derived from a pastel, also produced by Smith in 1800. (C) The Wellcome Trust Medical Photographic Library.

only in items such as the commemorative stamp issued in 1999, but also in artefacts (keyrings, bookmarks) produced for and sold by the Jenner Museum in Berkeley, Gloucestershire, which is located in Jenner's own house. After the German medal produced in 1796, the first recorded portrait of Jenner is the lovely pastel executed in 1800 by John Raphael Smith, which has spawned a remarkable number of derivatives, initially in print form (Figure 2), and more recently in the form, for example, of a cheap mug on sale at the 


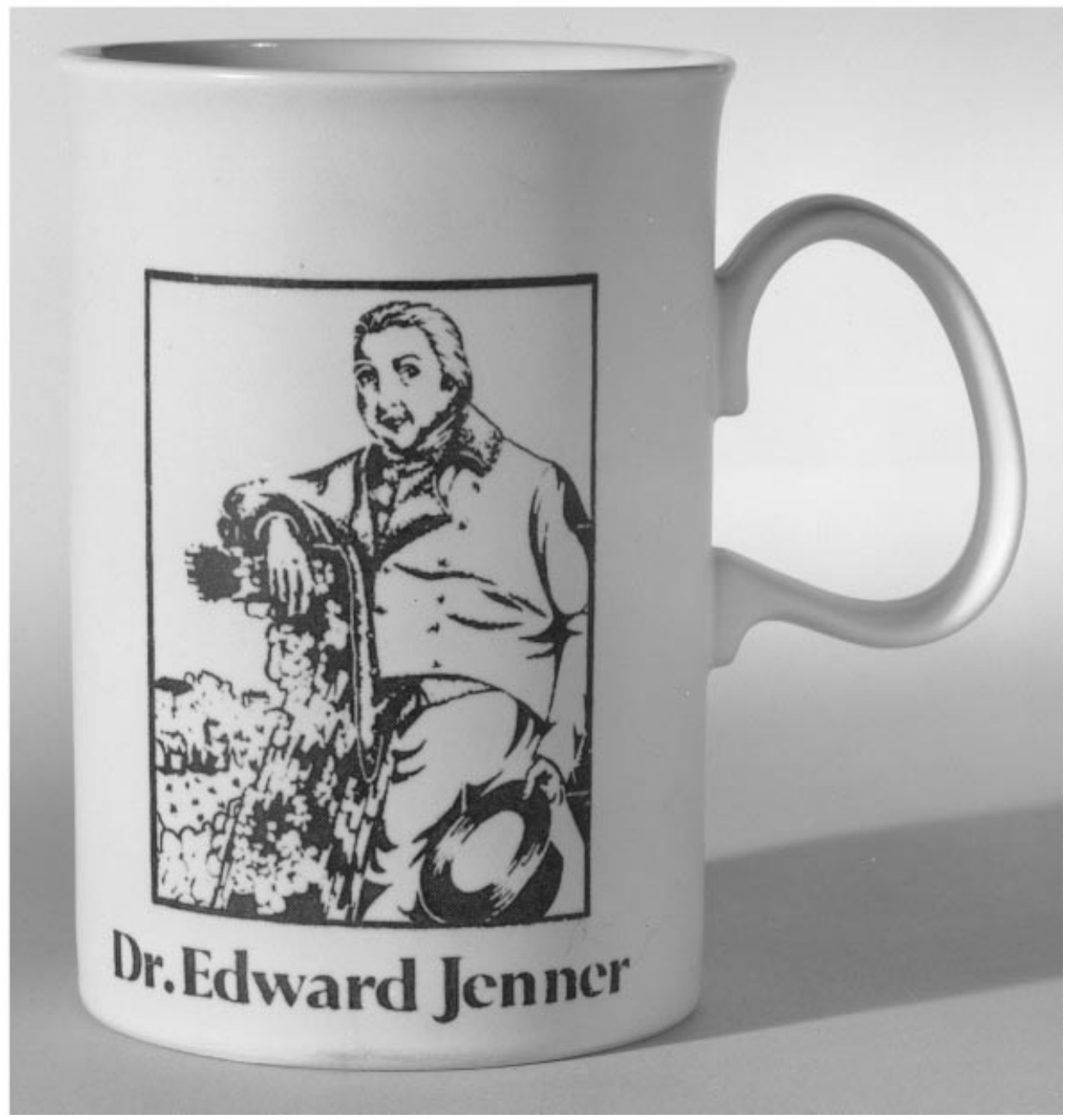

Figure 3. Porcelain mug, decorated with an image of Edward Jenner derived from John Raphael Smith's portrait, on sale at the Jenner Museum, Berkeley, Gloucestershire. (C) National Portrait Gallery, London.

Jenner Museum (Figure 3). ${ }^{35}$ If we probe Smith's image a little, three features become apparent. First, it is a country scene; although Jenner spent time in London, he preferred a more countrified existence. He evidently was, and was frequently represented as being, a man who enjoyed the country life available to the gentry. Second, the scene includes cows

35 These items are illustrated in Jordanova, op. cit. (2), 117 (medal); 91 (stamp/keyring); 86 (bookmark); 32 (mug); 88 (Jenner's study in the museum); 107 (Smith pastel). Derivative prints from the Smith are listed in Burgess, op. cit. (2). On Smith, see E. D’Oench, 'Copper into Gold': Prints by John Raphael Smith 1751-1812, New Haven and London, 1999. 
and dairymaids, which extends the information given about Jenner's activities, while providing further symbols, especially the cow. Third, Jenner himself is in country squire mode; leaning back on a tree, he looks confident, as if he is about to leap into the saddle - he was particularly fond of riding and rustic jollities. He is not depicted as learned or intellectual.

Shortly after Smith's portrait was produced, James Northcote, who had been a pupil and protégé of Sir Joshua Reynolds, painted Jenner twice. One canvas is in the National Portrait Gallery in London, the other is in Plymouth and belongs to the Medical Society. The prime movers behind the Plymouth picture were men with a passionate enthusiasm for Jenner and his technique, and in one case, strong personal ties as well. It is noteworthy that they commissioned Northcote, who, like Reynolds, came from the Plymouth area, to paint a portrait of Jenner to indicate their support for his work. The elaborate frame records the name of the main benefactor, and thus the commemoration is not just of Jenner himself but of both the patrons and the institution. Prints were derived from both the Northcote portraits, and both contain specific indicators of Jenner's distinctive achievements. But he is represented in a mode quite different from that of the Smith portrait; here Jenner is the man of learning, inside. There were other portraits in oils, for example by Sir Thomas Lawrence and by William Armfield Hobday, and other prints, such as the extraordinary one based on a drawing by Drayton, who was a friend of Jenner's and engraved, it would seem, at the sitter's expense. ${ }^{36}$ Baron's Life does not discuss the portraits in any detail, but he says enough to indicate that sitting for portraits was part of the obligations of a man with a public reputation, that Jenner had marked preferences among the portraits and that portraits were topics of conversation and items of exchange. One absolutely central point comes over in Baron's account, and indeed it is perfectly clear from the pictures in question: the doubly close relationship between Northcote's portraits of Jenner and Reynolds's portrait of John Hunter. Northcote was a pupil of Reynolds, Jenner was a pupil of Hunter. The Reynolds spawned many prints, but the finest is generally agreed to be that of Sharpe (1788), who started to engrave one of the Northcote portraits as a companion piece, but died before it was finished. Hunter was a major figure in Jenner's life: He was Jenner's teacher, godfather to his son and a constant correspondent on matters medical and scientific. Hunter had died in 1793 and in the years after his death he became a great hero of English medicine. In evoking two mentors, Reynolds for himself and Hunter for his sitter, Northcote celebrated British achievements and evoked two lineages, in art and medicine respectively. One generation invokes and pays homage to the previous one. ${ }^{37}$

It seems to have been a feature of eighteenth- and early nineteenth-century science and medicine that immediate predecessors were highly valued. A gradual shift seems to have occurred in this respect. The ancients were still important, especially in the first two thirds of the eighteenth century, but gradually it became increasingly common to record modern

36 The Lawrence is in the Royal College of Physicians, the Hobday at the Royal Society of Medicine, the Drayton is number 1527.27 in Burgess, op. cit. (2).

37 The Northcote portraits are illustrated in Jordanova, op. cit. (2), 94 (Northcote's first portrait); 102 (Lawrence's portrait of Jenner); 120 (Sharpe's print from Reynolds's portrait of John Hunter); 121 (print after Northcote's second portrait of Jenner). 
antecedents. For example, John Coakley Lettsom, a medical do-gooder with a strong interest in history, including ancient history, used a silhouette of Jenner on the frontispiece of a book published in 1801, which is a form of elevation by association with contemporary achievement. ${ }^{38}$ Since Lettsom was an extremely active participant in the vaccination controversies, we have here a case of commemoration being integral to the events themselves, which are thereby given a lofty position that belies both their contemporaneous status and the involvement of interested parties.

A particularly good example of the point is the gold medal given to Jenner in 1801 by the medical officers of the British Navy. Here we return to the question of names, since on neither side of this medal was there a portrait of Jenner. Instead they used his name. One side simply records the name of the reigning monarch, the date and the name of the person in charge of naval administration at the time. It is decorated by an anchor. The other side, according to Baron, 'represents Apollo as the god of physic introducing a young seaman, recovered from the vaccine inoculation, to Britannia; who, in return extends a civic crown, on which is written JENNER '. ${ }^{39}$ In this case the name 'Jenner' was sufficiently eloquent to invoke the man. The medal was sent to Jenner accompanied by a letter from Dr Thomas Trotter, the author of a number of works on naval medicine. In Baron's estimation the whole episode reflected well on both men - elevation by association again. Trotter was writing on behalf of his fellow naval doctors, and like so many who praised Jenner and his achievements, he wanted its universal benefits to be acclaimed. It is therefore significant, I think, that he refers to the Navy as a 'department of public service', since this simultaneously reinforces the public value of what Jenner had achieved, and implies that the Navy is a useful testing ground for medical innovation. Trotter's turn of phrase displays the universalism that has so often been a central part of celebrating scientific and medical achievements: 'May you be blessed with length of days to see your discoveries the means of abridging and preventing disease, pain, and deformity throughout the habitable globe'. ${ }^{40}$

There is little special in these words; in one form or another such sentiments were commonplace in the celebration of scientific, medical and technological achievement. But they nonetheless bear in interesting ways on the themes of this address. We can observe the use of a traditional form of acknowledgement - the medal-and the deployment of classical motifs - Apollo and the crown. The inclusion of Britannia is equally significant. She was a common figure by this time, in prints, for example; she obviously carries a sense of national pride, and serves to annex Jenner specifically to the nation's maritime achievements. ${ }^{41}$ So far, the references are to past and to present times. But Trotter's letter, like so much that was written about Jenner and vaccination, invokes the future too - not any old future but a better one produced by science. The entire human race, no matter

38 Illustrated in Jordanova, op. cit. (2), 93.

39 Baron, op. cit. (1), 1st edn., 405.

40 Baron, op. cit. (1), 1st edn., 407.

41 On Britannia, see D. Donald, The Age of Caricature: Satirical Prints in the Reign of George III, New Haven and London, 1996; L. Colley, Britons: Forging the Nation, 1707-1837, New Haven and London, 1992; on the window in the Wren Library that includes Newton, Bacon and Britannia, see McKitterick, op. cit. (8), 25-6 and Figs. 13 and 14; Thomas Arne's 'Rule Britannia' was first performed in 1740. 
where it resides, will benefit. There is a form of utopianism here; to imagine that human skill, insight and ingenuity can eradicate a disease is to imagine an improved future, one produced not by providence but by a special group of people.

\section{Conclusions}

I have noted the development of graspable units, flexible cultural elements, for representing the achievements of science and medicine. These were the building blocks for the commemoration of science and frequently they were formed as an integral part of the scientific and medical practices they celebrated. I see these forms of representation as occurring in a number of registers. Some of these can only be fully read by peer groups and those who work most closely with them. Others address audiences with no specialist knowledge at all. I have suggested, furthermore, that there are special challenges to be met in representing the more abstract aspects of natural knowledge to general publics. It follows that areas of technology, where there are machines that can be made appealing in some way, are at a considerable advantage - as the displays at the Science Museum in London reveal. Tags are developed to act as cultural bridges. These frequently take visual form, and play upon the idea and/or name of selected individuals. In each case, the individual is molded so that their tag-functions work as effectively as possible, and the molding processes are historically contingent. In the late eighteenth and nineteenth centuries the prime movers behind such processes were, at least initially, peer groups, coteries, followers and friends who worked in collaboration with other key groups. Two in particular assumed special importance. On the one hand we have artists, sculptors, print makers and so on, including entrepreneurs such as Wedgwood and Bentley, who produced series of medallions. ${ }^{42}$ On the other, we have writers, translators and publishers, editors of magazines, scientific journalists and so on, including men such as Henry, Lord Brougham, who acted as a classy male midwife for scientific values in nineteenth-century Britain. ${ }^{43}$ Visual culture, material culture and print culture are, in fact, inseparable; bridges could be built and tags deployed effectively because of the complex overlapping networks between the makers of culture and the makers of natural knowledge. These encouraged artists and sculptors to be sensitive to the social complexities that their scientific and medical sitters found themselves navigating. ${ }^{44}$

I could make these points too by invoking the notion of identification. Representations of practitioners elicit forms of identification in viewers and readers. The processes whereby this occurs are horrendously complex, and only minuscule amounts of direct evidence exist to help us unravel them. I have begun to wonder whether the interest in anniversaries is not best seen in this light. In the case of Jenner, there was the constant emphasis on his

42 A Catalogue of Cameos, Intaglios, Medals ..., London, 1779.

43 J. G. Crowther, Statesmen of Science, London, 1965, 9-73.

44 For example, Allan Ramsay's friendships with Richard Mead and William Hunter, or Chantrey's with James Watt, arguably led to just such sensitivity. Both Ramsay's portraits are illustrated in Jordanova, op. cit. (2) as is a statue of Watt by Chantrey, who also produced a bust: 28, 160, 161, 65. 
birthday. Birthdays, like dates of death and publication, are familiar, easy to identify with and, if I can put it this way, unitary. They take place on a particular day, which becomes a natural tag. We know perfectly well that in reality the processes of birth and death, just like those of publication, can be protracted, but by convention we take one aspect of them as the sole crucial moment. Clearly death is significant because it permits not only rituals but specific kinds of celebration that are only possible and appropriate when the person in question is no longer present. Historians have paid considerable attention to death and its memorialization in recent times. I simply want to reiterate the point that much careful cultivation of reputations went on during the lifetime of a limited number of key figures - prefigured commemoration if you like.

Yet the example of Jenner prompted me to think about birthdays in particular, beyond the obvious fact that they are already available during a lifetime. Perhaps I can speculate a little bit here about the attraction of birthdays as tags. Two features of them may be pertinent here: first, they are anticipatory ('many happy returns'), that is, they look forwards into the future; second, they relate to the most powerful metaphor of origination that we have. I have been hinting both that utopian ideas about the efficacy of science and medicine gave their commemoration a futuristic cast and that those most enthusiastically celebrated were associated with the creation of an original idea. It is possible then that there was a rather good match, for example in Jenner's case, between his achievements and the idea of a birthday. I wish not to be misunderstood on this point: there was little inherent in the achievements that did this, it was how they were represented. Jenner's originality was not self-evident; these claims had been carefully cultivated. It was precisely in the face of huge conflicts around vaccination as a technique and who was to take credit for it that Jenner was celebrated.

I have deliberately used the word remembrance to suggest a wide range of ways in which the past is evoked and their capacity to infuse one's being. I suspect that although we professional historians - know about this range, we generally package some parts of it rather carefully as heritage, public history or popular history. It would require another paper to work through the arguments about the role of specialized, professionalized, academic history in relation to these broader concerns. But the relationships between them, however unclear, need to be examined, not least because they are in constant interplay. ${ }^{45}$

I want to close on an open-ended note by referring to a piece of material culture, a portrait in fact, which evokes for me many of the issues I have mentioned. It is the statue of a famous 'scientist', the naturalist Jean-Baptiste Lamarck (1744-1829), who has been dubbed 'the founder of evolution'. He was the subject of my doctoral thesis, submitted more than twenty years ago. One of the points that struck me most forcibly then was the varied and contradictory afterlives he enjoyed ${ }^{46} \mathrm{He}$ continued to be a living presence for many of those who worked on evolution in the twentieth century. The book that is generally seen as his magnum opus, the Philosophie zoologique, was published in 1809.

45 L. Jordanova, History in Practice, London, 2000, especially Chapter 6.

46 L. Jordanova, The Natural Philosophy of Lamarck in its Historical Context, unpublished Ph.D. thesis, University of Cambridge, 1976, especially Chapters 1 and 2; cf. L. Jordanova, Lamarck, Oxford, 1984, especially Chapter 10. 
The statue in question stands in the Jardin des Plantes, Paris, where Lamarck lived and worked most of his life, and where his papers and collections are still housed; it commemorates the centenary of this major publication. The pose of the statue itself $-\mathrm{a}$ seated figure, head on hand - is eloquent, and it is in a recognizable tradition for depicting learned, thoughtful, introspective men. On the pedestal is a relief of Lamarck as an old man with one of his daughters: 'La Postérité vous admirera, elle vous vengera, mon père', she declaims. ${ }^{47}$ Viewers are invited to identify with a blind, neglected old man, to bring into their minds his achievements, already a century old when the statue was erected, while at the same time imagining a future where they will be justly acknowledged. Lamarck's statue epitomizes for me the theme - remembrance of science past.

47 The statue is by Léon Fagel; on Lamarck see P. Corsi, The Age of Lamarck: Evolutionary Theories in France, 1790-1830, Berkeley, 1988. 